\title{
A study of assess the prevalence of dry eye and its associated risk factors in a tertiary care hospital
}

\author{
Saxena R.K. \\ Dr. Ram Krishna Saxena, Assistant Professor at G.C.R.G Institute of Medical Sciences, BKT, Lucknow, U.P, India. \\ Corresponding Author- Dr. Ram Krishna Saxena, Assistant Professor, Address- Atasaria House Manas Enclave Road, \\ Fridinagar, Lucknow U.P. E-mail:- rksaxena1303@gmail.com
}

\begin{abstract}
Introduction: Dry eye is a major tear deficiency disorder which affects millions of people worldwide. Dry eye refers to disorders of the tear film due to reduced tear production and/or excessive tear evaporation associated with symptoms of ocular discomfort. Material and Methods: This was a descriptive, cross sectional study carried out at Ophthalmology out-patient department (OPD) of G.C.R.G Institute of medical sciences BKT Lucknow U.P. from December 2016 to March 2018. Results: In our study, among all the associated risk factors majority of the patients 58 (58\%) had dry eyes due to other causes which includes pterygium, conjunctivitis, blepharitis, vitamin A deficiency and senile. 17 (17\%) patients were found with allergy\& keratitis was found in $12(12 \%)$ patients. Conclusion: Proper counseling of the patients regarding the chronic nature disease with long term treatment and preventive measures are necessary to relieve ocular discomfort and ensure patient satisfaction with a better quality of life.
\end{abstract}

Keywords: Dry eye, Risk factors, Visual acuity, Refraction and Tear film test

\section{Introduction}

Dry eye is a major tear deficiency disorder that affects millions of people worldwide [1]. Dry eye refers to disorders of the tear film due to reduced tear production and/or excessive tear evaporation associated with symptoms of ocular discomfort [2].

Patients with dry eye often complain of pain, heaviness, foreign body sensation, redness, photophobia and reflex watering due to corneal irritation. Because the tear film in dry eye patients is unstable and incapable of maintaining the protective qualities that are necessary for its structure and function, patients experience the symptoms of discomfort associated with dry eye, which are burning, stinging, grittiness, foreign body sensation, tearing, ocular fatigue, and dryness. Patients may complain of symptoms of dry eye in the presence or absence of signs of the disease [3].

The prevalence of Dry Eye Disease (DED) is greatly influenced by geographic location, climatic conditions, and lifestyle of the people and ranges from 5\% to $35 \%$ [4-6].Very few studies have described the epidemiology of DED from the Indian subcontinent [7-9].

Manuscript received: $30^{\text {th }}$ September 2018

Reviewed: $9^{\text {th }}$ October 20178

Author Corrected: $15^{\text {th }}$ October 20178

Accepted for Publication: $22^{\text {th }}$ October 2018

Tropical Journal of Ophthalmology and Otolaryngology
Various risk factors for dry eye alluded to in literature include air pollution, cigarette smoking, low humidity, high temperature, sunlight exposure and drugs [10].

The objective of our study is to find out the prevalence of dry eye disease and to study the various factors associated with the dry eye disease in patients attending ophthalmology out-patient department in tertiary care hospital.

\section{Material and Method}

This was a descriptive, cross sectional study carried out at Ophthalmology out-patient department (OPD) of G.C.R.G Institute of medical sciences BKT Lucknow U.P. from December 2016 to March 2018. NonProbability purposive sampling was used for selection of patients. The sample size was calculated from the formula $4 \mathrm{Pq} / \mathrm{l}^{2}$ by taking $5 \%$ margin of error, $95 \%$ Confidence interval. The required sample size was found to be 100 .

Inclusion criteria: Patients attending ophthalmology OPD with age above 18 years with presenting complaint consistent with dry eyes (ocular discomfort, burning sensation, redness, itching, dryness etc) were included in this study. 


\section{Original Research Article}

Exclusion criteria: Patients taking any ocular or systemic medications, or had undergone intra or extra ocular surgery or with an active ocular infection in the previous 6 months were excluded from the study and patient who did not gave consent were excluded.

Procedure- After taking consent from all the subjects included in the study, a detailed history about demographic, medical, lifestyle data and symptoms of dry eye such as dryness, grittiness, burning, stickiness, heaviness, itching and watering was taken. All the patients were checked by Auto-refractometer, Visual acuity, Refraction, and Tear film test by slit lamp. Local anesthesia, Fluorescein strips and Schirmer's test.

Data analysis- The data was analyzed through the software Microsoft office excel 2007. The entire continuous variables were presented as Mean \pm SD. All categorical variables were presented as frequency and percentages.

\section{Results}

In or study, a total of 100 patients were included in the study, of which $56(56.0 \%)$ were males and $44(44.0 \%)$ were females. The most common age group affected was 21-30 years followed by 31-40 years in both the sexes. Out of total 56 males $12(12 \%)$ and out of total 44 females $13(13 \%)$ had dry eye disease. Age wise distribution of dry eye disease patients is shown in Table No.1.

Table No.-1: Distribution of dry eye disease patients

\begin{tabular}{|c|c|c|c|c|c|c|}
\hline Age in years & $\begin{array}{c}\text { Males } \\
\mathbf{n}(\%)\end{array}$ & $\begin{array}{c}\text { DED } \\
\mathbf{n}(\%)\end{array}$ & $\begin{array}{c}\text { Females } \\
\mathbf{n}(\%)\end{array}$ & $\begin{array}{c}\text { DED } \\
\mathbf{n}(\%)\end{array}$ & $\begin{array}{c}\text { Total } \\
\mathbf{n}(\%)\end{array}$ & $\begin{array}{c}\text { DED } \\
\mathbf{n}(\%)\end{array}$ \\
\hline$<21$ & 04 & $01(01)$ & 02 & $01(01)$ & 06 & $02(02)$ \\
\hline $21-30$ & 18 & $04(04)$ & 15 & $04(04)$ & 33 & $08(08)$ \\
\hline $31-40$ & 15 & $03(03)$ & 11 & $03(03)$ & 26 & $06(06)$ \\
\hline $41-50$ & 12 & $02(02)$ & 08 & $02(02)$ & 20 & $04(04)$ \\
\hline $51-60$ & 05 & $01(01)$ & 09 & $02(02)$ & 14 & $03(03)$ \\
\hline Above 60 & 03 & $01(01)$ & 01 & $01(01)$ & 04 & $02(02)$ \\
\hline Total & $\mathbf{5 6}$ & $\mathbf{1 2}$ & $\mathbf{4 4}$ & $\mathbf{1 3}$ & $\mathbf{1 0 0}$ & $\mathbf{2 5}$ \\
\hline
\end{tabular}

In our study, majority of the patients $25(25 \%)$ had mixed presenting complaint i.e. a combination of two or more symptoms which was followed by watering in eyes and itching in eyes. Distribution of dry eye disease patients according to the presenting complaints is shown in Table No.2.

Table No.-2: Distribution of patients of dry eye disease according to presenting complaints

\begin{tabular}{|l|c|}
\hline Presenting Complaints & n (\%) \\
\hline Burning Sensation & 12 \\
\hline Itching & 15 \\
\hline Redness & 09 \\
\hline Photophobia & 08 \\
\hline Watering & 24 \\
\hline Grittiness & 06 \\
\hline Foreign body sensation & 11 \\
\hline Combination of 2 or more of above complaints & 25 \\
\hline Total & $\mathbf{1 0 0}$ \\
\hline
\end{tabular}

In our study, among all the associated risk factors majority of the patients $58(58 \%)$ had dry eyes due to other causes which includes pterygium, conjunctivitis, blepharitis, vitamin A deficiency and senile. 17 (17\%) patients were found with allergy, keratitis was seen in $12(12 \%)$ patients. Distribution of patients of dry eye disease according to risk factors is shown in Table No. 3. 
Table No.-3: Distribution of patients of dry eye disease according to risk factors

\begin{tabular}{|l|c|}
\hline Risk factor for Dry Eye Disease & n (\%) \\
\hline Keratitis & 12 \\
\hline Allergy & 17 \\
\hline Contact lens & 01 \\
\hline Computer or Mobile use & 09 \\
\hline Drugs/Medications & 03 \\
\hline Others (pterygium, Conjunctivitis, Blepharitis, Vit-A def., Senile) & 58 \\
\hline Total & $\mathbf{1 0 0}$ \\
\hline
\end{tabular}

\section{Discussion}

In or study, a total of 100 patients were included in the study, of which $56(56.0 \%)$ were male and $44(44.0 \%)$ were female. The most common age group affected was 21-30 years followed by 31-40 years in both the sexes. Out of total 100 patients $25(25 \%)$ patients had dry eye disease which include 56 males $12(12 \%)$ and 44 females $13(13 \%)$. Proportion of DED was seen more common in females.

In a study conducted by Anuj Kumar Pathak et al [11] in Jharkhand in 2017, the proportion of dry eye patients diagnosed in their study was $39.3 \%$ which was lower than the study done at West Bengal [12] where it was around $54 \%$ and higher than the study conducted by Bhutia et al [13] in Sikkim where it was around $12.7 \%$. Thus the proportion of dry eyes varies in different geographical locality.

In our study, majority of the patients $25(25 \%)$ had mixed presenting complaint i.e. a combination of two or more symptoms which was followed by watering in eyes and itching in eyes. In a similar type of study conducted by Shah S [14] in 2015, out of 400 patients who had dry eye, eye watering (41\%) and itching $(19.8 \%)$ were the most common symptoms

In our study, among all the associated risk factors majority of the patients $58(58 \%)$ had dry eyes due to other causes which includes pterygium, conjunctivitis, blepharitis, vitamin A deficiency and senile.

$17(17 \%)$ patients were found with allergy, keratitis was seen in $12(12 \%)$ patients. In a similar type of study conducted by Shaheerah G [15], 63\% were having the symptoms of dry eyes due other causes which includes pterygium, conjunctivitis, blepharitis $22 \%$ of the patients were included in allergy, some patients were having keratitis, few were having dry eye due to use of several drugs.

\section{Conclusion}

There are many contributing factors for dry eye which includes age, female gender, medications and contact lens use. This study reflects a major burden of DED among the routine outpatients in tertiary care institute and this was reflecting an adverse impact on the vision related quality of life on patients having various dry eye symptoms. Proper counseling of the patients regarding the chronic nature disease with long term treatment and preventive measures are required to relieve ocular discomfort and ensure patient satisfaction with a better quality of life.

\section{Funding: Nil, Conflict of interest: Nil} Permission from IRB: Yes

\section{References}

1. Goto E, Yagi Y, Matsumoto Y, Tsubota K. Impaired functional visual acuity of dry eye patients. Am J Ophthalmol. 2002 Feb;133(2):181-6.

2. De Haas EB. The Pathogenesis of Keratoconjunctivitis Sicca. Ophthalmologica. 1964; 147:1-18.

3. Gayton JL. Etiology, prevalence, and treatment of dry eye disease. Clin Ophthalmol. 2009;3:405-12. Epub 2009 Jul 14.

4. The epidemiology of dry eye disease: report of the Epidemiology Subcommittee of the International Dry Eye Work Shop (2007). Ocul Surf. 2007 Apr;5(2):93107.

5. McCarty CA, Bansal AK, Livingston PM, et al. The epidemiology of dry eye in Melbourne, Australia. Ophthalmology. 1998 Jun; 105 (6): 1114-9. DOI:10. 1016/S0161 - 6420(98)96016-X 


\section{Original Research Article}

6. Lin PY, Tsai SY, Cheng CY, et al. Prevalence of dry eye among an elderly Chinese population in Taiwan: the Shihpai Eye Study. Ophthalmology. 2003 Jun; 110 (6): 1096-101. doi: 10.1016 / S0161 - 6420 (03) 00262-8

7. Gupta N, Prasad I, Jain R, D'Souza P. Estimating the prevalence of dry eye among Indian patients attending a tertiary ophthalmology clinic. Ann Trop Med Parasitol. 2010 Apr; 104(3):247-55. doi: 10.1179/ $136485910 X 12647085215859$.

8. Basak SK, Pal PP, Basak S, et al. Prevalence of dry eye diseases in hospital-based population in West Bengal, Eastern India. J Indian Med Assoc. 2012 Nov;110(11):789-94.

9. Rege A, Kulkarni V, Puthran N, Khandgave T. A Clinical Study of Subtype-based Prevalence of Dry Eye.

J Clin Diagn Res. 2013 Oct;7(10):2207-10. doi: 10.7860/JCDR/2013/6089.3472. Epub 2013 Oct 5.

10. Hikichi T, Yoshida A, Fukui Y, et al. Prevalence of dry eye in Japanese eye centers. Graefes Arch Clin Exp Ophthalmol. 1995 Sep;233(9):555-8.
11. Anuj Kumar Pathak, M. Deepak Lakra, Rajiv Kumar Gupta. Study to assess dry eye among patients of a tertiary care hospital in Jharkhand. International Journal of Contemporary Medical Research 2017;4(9):1861-1864.

12. Basak SK, Pal PP, Basak S, et al. Prevalence of dry eye diseases in hospital-based population in West Bengal, Eastern India. J Indian Med Assoc. 2012 Nov;110(11):789-94.

13. Bhutia KL, Lomi N. A hospital-based study to estimate the proportion of dry eye cases among patients attending the Tertiary Care Hospital, Gangtok, Sikkim. Sudanese J Ophthalmol [serial online] 2016;8:42-5.

14. Shah S, Jani H. Prevalence and associated factors of dry eye: Our experience in patients above 40 years of age at a Tertiary Care Center. Oman J Ophthalmol. 2015 Sep-Dec;8(3):151-6. doi: 10.4103 /0974 -620X.169910.

15. Shaheerah G, Adil S J, Muhammad F F. Frequency and Risk Factors of Symptomatic Dry Eye Disease at Tertiary Care Eye Hospital, Karachi. Biostat Biometrics Open Acc J. 2018; 4(3): 1-5.

\section{How to cite this article?}

Saxena R.K. A study of assess the prevalence of dry eye and its associated risk factors in a tertiary care hospital. Trop J Ophthalmol Otolaryngol.2018;3(4):75-78.doi: 10.17511/jooo.2018.i04.03 